\title{
Discussion on the Application of Cloud Accounting in Enterprise Accounting Informatization
}

\author{
Nana Huang \\ Chengdu Normal University, Chengdu Sichuan, 611130, China
}

Keywords: Cloud accounting, Enterprise, Accounting informatization.

\begin{abstract}
Cloud accounting provides accounting, management and decision-making services provide accounting, management and decision-making services for the relevant units, including enterprises on the basis of Internet technology. Comparing with other accounting services, accounting cloud has a significant competitive advantage both low costs which can reduce the costs of business, and high efficiency, which can greatly enhance the working efficiency of enterprise financial accounting. Therefore, the cloud accounting has a very good use value in enterprise accounting informatization. This paper makes an overview of the cloud accounting and accounting informatization, analyzes the advantages of cloud accounting application in enterprise accounting informatization, and discusses the application strategy of cloud accounting in enterprise accounting informatization.
\end{abstract}

\section{Introduction}

Due to the continuous development of China's social economy, enterprises have become the main force to promote the sustained development of China's economy, and play an important role in the overall economic level of China's increase. In recent years, cloud accounting has been one of popular topics of theory circles which can combine the accounting information processing with network technology, thereby effectively curing deficiencies in traditional information processing means. So, this new accounting application mode can greatly control and reduce the costs of enterprises. The practical application based on the analysis of cloud accounting in the enterprise accounting informatization, have a great practical significance in accelerating the transformation process of the modernization of enterprise management, enhancing the real competitiveness of China's enterprises and promoting the informatization development of China's society.

\section{An overview of cloud accounting and accounting informatization}

The so-called cloud accounting, mainly refers to the technology which can achieve the collection and storage of accounting information by the use of various means, and then establish a large database. The big data base here is actually "cloud". After the connection with network, you can browse the information though cloud data. Under this premise, cloud accounting can provide online accounting, management and decision-making services for enterprises. Cloud accounting can achieve a variety of functions in the enterprise accounting practice, in which the data storage function is to flexibly store the information. The function of the service platform is to provide the data information which is needed for the enterprise accounting related work in the cloud computing. Accounting information mainly refers to summarize, analyze, and process the enterprise accounting information. In a broadest sense, the accounting information refers to realize the works related to information in the enterprise, for example, software research and development of enterprise financial accounting, the construction, application, and maintenance of enterprise accounting information system, and talents cultivation of enterprise accounting informatization, the oriented objects are quite widespread, which mainly focus on overall mechanism construction of accounting informatization. In the narrow sense, accounting information refers to taking computer technology as the main body, applying it to the actual accounting work, integrating all kinds of accounting information, comprehensively developing 
the relevant accounting resources, and strengthening the supervision and management of accounting information to achieve the sustainable development of the enterprise accounting work.

\section{The advantages using cloud accounting in enterprise accounting informatization}

First, it can be very good to compress the expenditure of enterprise accounting. Through the use of cloud accounting technology, it can greatly control and decrease the cost of management accounting in enterprises, mainly reflected in the following aspects: first, the cloud accounting has professional software development company, so it can develop the mature software which is the most suitable for the enterprise according to the enterprise accounting project, as long as the enterprises pay the software, they can get the application of the relevant technology, so as to greatly reduce the costs that the enterprises need to pay for the projects, and consistently update with market software, and the companies do not need to worry about the technical aspects of the problem. At the same time, because a cloud accounting technology can be used in a number of enterprises, on average, the cost of the acquisition of software companies is still low. Secondly, in order to better serve enterprises, software companies can work out differentiated purchase program according to their own actual operation situation, even can flexibly select the required period of time, so as to save expenditure. Finally, the software company also can provide maintenance services, so that the enterprise can save a lot of costs like software maintenance, updating and others.

Second, the ability to improve enterprise accounting information management. Cloud accounting technology development company has a very professional technology development and management team, which can not only implement technology research and development and improvement work, but also carry out software updates, traps and other services in accordance with the actual situation of the current market. The supports from such a powerful technology are difficult to achieve for all enterprises who rely on their own strength. However, because the cloud of accounting technology popularization and application and technology continues to tend to mature, and cloud accounting technology development also has the corresponding market share, therefore, the companies don't need to worry about technology of pressure if using cloud computing technology, what is need is only to purchase the most suitable cloud accounting software in accordance with their own actual situation. At the same time, under the support of a strong technical team, the company's cloud accounting capabilities will be able to get faster and more reasonable improvement.

Third, it can better improve the practical ability of enterprise accounting information. Because the achievement of specific application of the cloud accounting technology must depend on the computer network, so the work will not be effected by space and time, and accountants can work timely and quickly, which makes the work more practicality and flexibility. One of the important advantages of cloud accounting is that the computational speed greatly exceeds the artificial calculation speed, and it can implement various types of data analysis, as long as the operator inputs various types of instructions, cloud accounting can automatically generate all kinds of report forms, and these statements can become basic data for the business decision-makers to carry out the management. At the same time, the use of cloud accounting technology, build a platform for mutual communication between the enterprise and customers, so as to facilitate the transaction between the two, so that it can greatly enhance the working efficiency. Because the relevant data can be shared online, companies can use the network to carry out marketing activities, thus forming a new way of online sales. It can be said that this electronic operation mode is definitely a new development trend in the future development of the accounting profession.

\section{The application strategy of cloud accounting in enterprise accounting information}

\section{The reasonable choice of cloud accounting services and development enterprises}

The choice of cloud accounting services and development enterprises will directly affect the implementation of enterprise accounting information. Enterprises should carefully select the most suitable cloud accounting services and development enterprises based on their own actual situation. In this process, a variety of factors of the service enterprises should carry out a comprehensive 
consideration, such as the overall size, work experience, management capabilities, the successful case, the follow-up maintenance, market prices and the credibility. On this basis, what should also be gave full consideration to is whether the cloud accounting system offered by the providers is adequate security, whether it has a good stability and whether the technology is mature enough.

\section{Making cloud accounting service plan according to the enterprise actual situation}

Enterprises should choose the cloud accounting technology application services which is the most suitable for the enterprise practice by combining their own actual situation, mainly including the cloud leasing, private cloud and hybrid cloud,etc.. For those small and medium-sized enterprises with uncomplicated and less business, simpler management level, the cloud leasing can be applied; for those large enterprises with larger overall business volume and higher requirements to the information security and their own professional computer team and infrastructure equipment, the private cloud model can be used. Most of the other companies can use hybrid cloud mode based on the actual situation. Hybrid cloud can make private cloud and public cloud together to work coherently, so as to meet the flexible needs of enterprises. In the creation of cloud accounting, especially in the choice of private cloud or hybrid cloud, it should implement the overall planning, and do step-by-step implementation. For most enterprises, the implementation of cloud accounting is a very important information project. Information project needs a the overall planning, and do step-by-step implementation. Before the construction of cloud accounting, it should implement a clear overall planning based on the specific needs of enterprises, so as to define the objectives and direction of the information construction. The creation of cloud accounting can not be realized at once, but it needs to be implemented step by step according to the goal programming and the specific situation. In the implementation of cloud accounting, it should comprehensively manage and improve the financial accounting business process based on the actual characteristics of the enterprise and the cloud accounting technology. After the introduction of cloud accounting, its institutional organizations and business processes will be different from the previous one, naturally, it will often restructure the business process. Enterprises should comprehensively analyze the current management situation, implement more scientific, standardized transformation or restructuring process, and adjust the cloud accounting system according to the business process.

\section{Effectively enhance the supervision of government agencies}

One is to pay attention to the evaluation service of the supplier. First, the cloud computing is proposed by Google Corporation in the United States. Because the Google Corporation has received the appropriate management qualifications before the technical cooperation with the United States government. So, when improving and perfecting the information security law, our country must to comprehensively review the service quality of cloud accounting providers, reasonably improve the barriers to entry for cloud accounting industries, try to pick out the suppliers with a relatively high degree of integrity, relatively strong technical strength, so that we can ensure that the database is safe and we can establish more fair and equitable cloud accounting management situation. Two is to do a good job of follow-up education and third party supervision, etc.. To ensure the safety of accounting information through the establishment of third party regulatory agencies, to comprehensively review the cloud accounting services companies. Three is to improve and perfect the security laws and regulations of the cloud accounting information. At present, China's cloud accounting technology is not mature enough, and some potential problems have not been fully demonstrated, therefore it can not develop a more clear, more targeted guidance standards. So, we should formulate some standards related to cloud accounting technology according to the actual situation of the cloud computing technology development, then clear the future trend of the cloud accounting technology, continue to improve and perfect the cloud accounting development market, secure cloud accounting development direction to meet the accounting standards and norms, and perfect the relevant laws and regulations for cloud accounting technology development, to ensure that the enterprise accounting information can be kept safe.

\section{Enhance the management capabilities of cloud accounting information of enterprises}

Enterprises should design reasonable authority to conduct a reasonable authorization based on the content of the work and responsibilities of the staff. At the same time, it should be strict management and supervision of the authority, account number, password, and the account permissions change, and authorization should be signed by the highest decision-making enterprises before they can really take effect. At the same time, enterprises should communicate and cooperate with cloud accounting 
providers more positively, comprehensively record the browsing and use state of the relevant cloud accounting information, increasing the communication between enterprise and cloud accounting providers, so that it is more convenient for the enterprise managers to grasp the information of cloud accounting users, so as to prevent that accounting workers still retain the qualification to log in the relevant accounting information system after the resignation, thus preventing the effects for the security of accounting information. On this basis, enterprises should also set up the corresponding management system, in order to fully determine the responsibilities and various behavioral norms of employees, and earnestly ensure the security and confidentiality of enterprise information.

\section{Create high-quality cloud accounting professionals}

The application of cloud accounting technology brings new opportunities and challenges for enterprise financial accounting workers. This is because the requirements for the quality of cloud accounting technology professional talents are very high that they must have not only financial accounting professional knowledge, computer professional knowledge, but also the abilities of strong management, innovation and sustainable development, etc.. In order to create a high-quality cloud accounting professional talent team, the enterprises which introduce cloud accounting technology should not only focus on strengthening recruitment and the introduction of the relevant accounting information personnel, but should also continue to strengthen the training of existing accounting and information talents. The company strives to build a professional cloud accounting team through the efforts of two aspects.

\section{Conclusion}

In general, with the advent of big data age, once the enterprise wants to remain invincible in the increasingly fierce competition in the modern market, it should be better to adapt to the change of the situation, and committed to enhance the enterprise's production and management ability. Cloud accounting can not only improve the efficiency of work related to enterprise accounting, but also control the enterprises' costs in the accounting work, enhance the sensitivity for the market dynamics within the first time, and provide sustainable development strategy for the enterprise. Therefore, the enterprises must actively improve the quality and business capacity of accounting workers based on the actual situation of the current market. I firmly believe that with the deepening of economy mode of current market with Chinese characteristics and the maturity cloud computing tends to be, cloud accounting will be able to play a greater role in the enterprise accounting information in the future.

\section{References}

[1] Zhang Song. On the arrival of “cloud accounting age” in China, China Township Enterprises accounting, 2014(3).

[2] Zhang Yuan, Su Xuebi, Xie Liya. Research on the influence of cloud accounting on the financial management of small and medium-sized enterprises, International Business Accounting, 2014(4).

[3] Pi Chuncheng. Research on the advantages and disadvantages of cloud accounting in the application of accounting information in small and medium-sized enterprises, Shandong Textile Economy, 2014(8).

[4] Li Qianwen, Bai Xiaoyu, Yu Huan. Application of "Cloud Accounting” in accounting information of small and medium-sized enterprises, Market Modernization, 2014(27).

[5] Li Jing. On the application of "Cloud Accounting” in accounting information of small and medium-sized enterprises, Market Modernization, 2015(1).

[6] Zhang Yalei, Zhang Wenjun. Research on the application of accounting informatization in small and medium-sized enterprises based on big data and cloud computing, Science and Technology and Enterprise, 2015(7). 